\title{
Cardiac rhabdomyoma leading to an early neonatal death
}

\author{
M A M Wijayawardena ${ }^{1}$, H D P Gunawardene ${ }^{1}$, D Guneratne ${ }^{2}$, M V C De Silva ${ }^{3}$
}

Sri Lanka Journal of Child Health, 2004; 33: 89-90

(Key words: cardiac rhabdomyoma, neonate)

\section{Introduction}

Primary cardiac tumours are rare. Over $75 \%$ of them are benign ${ }^{1}$, the commonest being rhabdo-myoma. Cardiac rhabdomyomas are usually multiple (92\%) and often arise in the septum, ventricular wall or papillary muscles of infants and young children ${ }^{1}$. Here we describe a cardiac rhabdomyoma in a newborn, which occurred in the interventricular septum.

\section{Case report}

A 37 year old woman, in her second pregnancy, was found to have polyhydramnios. Antenatal ultra-sound scan revealed an enlarged fetal heart with a $3.6 \times$ $3.2 \mathrm{~cm}$ hyperechoic area in the interventricular septum of the heart. A live, non-asphyxiated baby girl, weighing $3.6 \mathrm{~kg}$, was delivered by vacuum extraction at term. Apgar score was 10 at birth. The baby's breathing became progressively difficult from two hours after birth and she died 25 hours after birth in spite of adequate resuscitation.

The baby had no dysmorphic features. The heart was enlarged (Figure 1) and weighed $100 \mathrm{~g}$. The great vessels were normally distributed. There was a large lobulated tumour originating from the interventricular septum and projecting into the right ventricle. The tumour markedly reduced the volume of the right ventricular cavity. There were no congenital cardiac malformations. The tumour was lobulated and tan white in colour. It measured $5 \times 4.5 \times 3 \mathrm{~cm}$ and weighed $70 \mathrm{~g}$ (Figure 2).

${ }^{1}$ Demonstrator, Department of Pathology, Faculty of Medicine, Colombo, ${ }^{2}$ Consultant Paediatrician, De Soysa Hospital for Women, Colombo, ${ }^{3}$ Professor, Department of Pathology, Faculty of Medicine, Colombo.

(Received on 25 March 2004) 


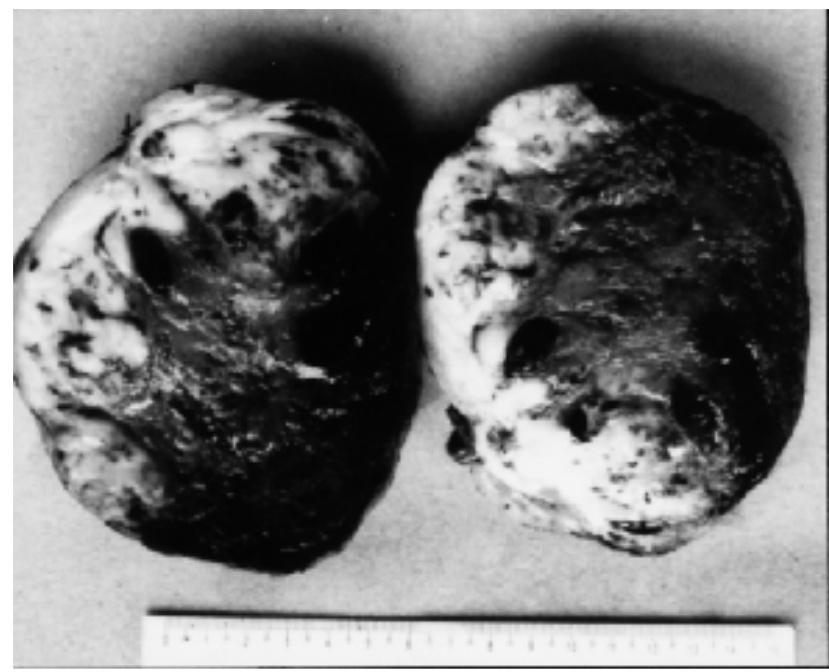

Figure 2. Cut section of the rhabdomyoma.

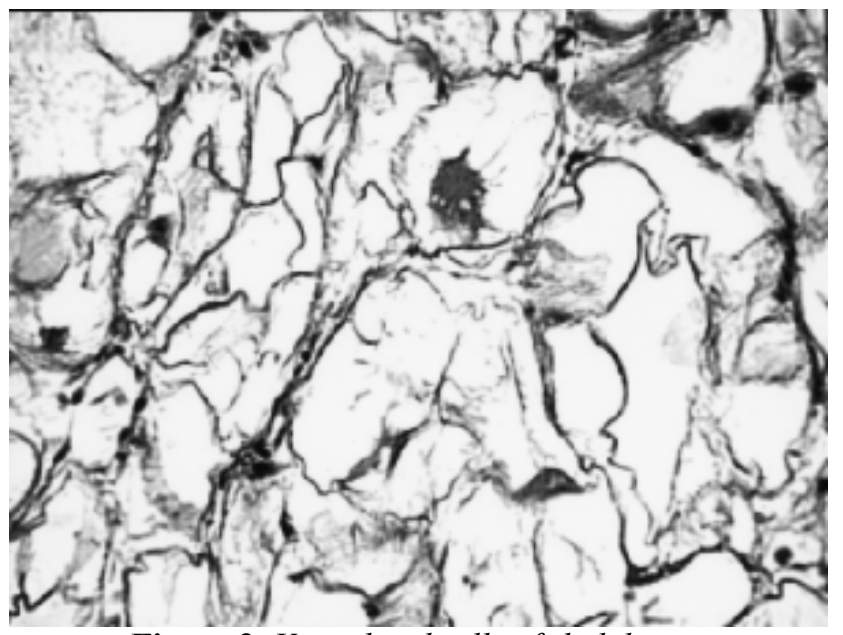

Figure 3. Vacuolated cells of rhabdomyoma

\section{Discussion}

Cardiac rhabdomyomas are currently regarded as hamartomas, most likely originating as a result of arrested cardiocyte maturation ${ }^{1}$. Various studies have shown that they are slow growing in-utero and show no or minimal postnatal growth. They often occur as multiple intramural lesions ${ }^{1}$. Although this patient did not have other features, in $30-80 \%$ of the cases it is associated with tuberous sclerosis ${ }^{1}$.

Clinical features of cardiac rhabdomyoma depend on the size, site and the number of tumours. The presenting features may be tachycardia, arrhythmia ${ }^{2,3}$, cardiac murmur, ventricular outflow obstruction ${ }^{4}$, complete or variable atrio-ventricular block, pericardial effusion, cardiomegaly, cardiac failure, Wolff-Parkinson-White syndrome ${ }^{5}$, or even sudden death. In the majority symptoms occur at early age or even before birth ${ }^{2,6}$. Cardiac dysrhythymias and nonimmune hydrops indicate poor prognosis.

Chest X-Ray is usually normal or non-specific. In large tumours distortion or focal engorgement of the cardiac contour is seen. It may also produce an apparent mediastinal mass. Ultrasound scan can be used antenatally to diagnose cardiac rhabdomyoma.

Echocardiography (transthoracic/transoeso-phageal) shows a variable sized tumour in the myocardium/cardiac masses. It is useful in determining the size, number, location and evaluation of haemodynamic consequences of tumours. Serial studies are useful and safe in monitoring tumour $\operatorname{size}^{7}$. The optimal technique for displaying intra and extra cardiac masses is the MRI. It can depict intracavity tumours, myocardial tumours and extension beyond the heart. Cardiac angiography and spiral CT can be used in the detailed evaluation of the cardiac lesion.

Multiple postnatal management options exist. If asymptomatic, a conservative management is advised. When cardiac outflow obstruction, persistent arrhythmias, cardiac failure or cardiogenic emboli are present, surgical resection may be considered. Rarely heart transplantation is indicated ${ }^{8}$.

Partial or spontaneous regression has been reported in $54 \%$ of cases. Regression may take place in a period as short as three weeks ${ }^{1}$. The chance of spontaneous regression does not depend on the initial size, number or location of the tumour. DiMario et al found that most lesions in patients followed with serial echocardiograms were undetectable by the age of 6 years ${ }^{9}$. Family screening for tuberous sclerosis is recommended.

\section{References}

1. Becker A E. Tumors of the heart and pericardium In: Fletcher C D $\mathrm{M}$ editor. Diagnostic histopathology of tumors. Vol 1, 2nd ed. London. Churchill Livingstone 2000.

2. Enbergs A, Borggrefe M, Kurleman N G, et al. Ventricular tachycardia caused by cardiac rhabdomyoma in a young adult with tuberous sclerosis. Am Heart $J$ 1996; 132:1263.

3. Muhler E G, Kienast W, Turniski-Harder V, et al. Arrhythmias in infants and children with cardiac tumors. Eur Heart J 1994; 15: 915. 
4. Stellingwerff G C, Hess J, Bogers A J. Left ventricular rhabdomyoma: a case report. $J$ Cardiovasc Surg 1999; 40: 131.

5. Bosi G, Lintermans J P, Pellegrino P A, et al. The natural history of cardiac rhabdomyoma with and without tuberous sclerosis. Acta Paediatr 1996; 85: 928.

6. Uzun O, McGawley G, Wharton G A. Multiple cardiac rhabdomyomas: tuberous sclerosis or not? Heart 1997; 77: 388.
7. Gulhis B, Resmiy B, Gulseren A, et al. Spontaneous Regression of Huge Cardiac Rhabdomyoma in An Infant. Images Paediatr Cardiol 2000; 5: 4-10.

8. Demkow M, Sorensen K, Whitehead B F, Rees P $\mathrm{G}$, et al. Heart transplantation in an infant with rhabdomyoma. Pediatr Cardiol 1995; 16: 204-6.

9. DiMario F J Jr, Diana D, Leopold H, et al. Evolution of cardiac rhabdomyoma in tuberous sclerosis complex. Clin Pediatr 1996; 35: 615. 